\title{
Giant Thoracolumbar Dumbbell Ganglioneuroma
}

\author{
Felipe José Santaella Pedro Tadao Hamamoto Filho \\ Gianfelipe Belini Poliseli Victor Azevedo de Oliveira Luis Gustavo Ducati \\ Marcelo Padovani de Toledo Moraes Marco Antônio Zanini \\ Department of Neurology, Psychology and Psychiatry, Botucatu Medical School, UNESP - Universidade Estadual \\ Paulista, Botucatu, Brazil
}

A 6-year-old girl presented with a history of 6 months of abdominal pain. On physical examination, she exhibited a large abdominal mass. No neurological abnormalities were observed. Magnetic resonance imaging (MRI) showed a large dumbbell contrast-enhancing mass from the right retroperitoneum to the spine, extending from T10 to L3. The tumor had eroded the vertebral bodies of L1 and L2 and enlarged multiple intervertebral foramens, as well as the spinal canal itself, displacing the spine to the left (Fig. 1). A 2-step resection was performed, first through a T11-L3 laminectomy for removal of the spinal component, then via laparotomy for resection of the retroperitoneal component. The patient had an uneventful postoperative recovery. Pathological analysis confirmed a ganglioneuroma (Fig. 2).
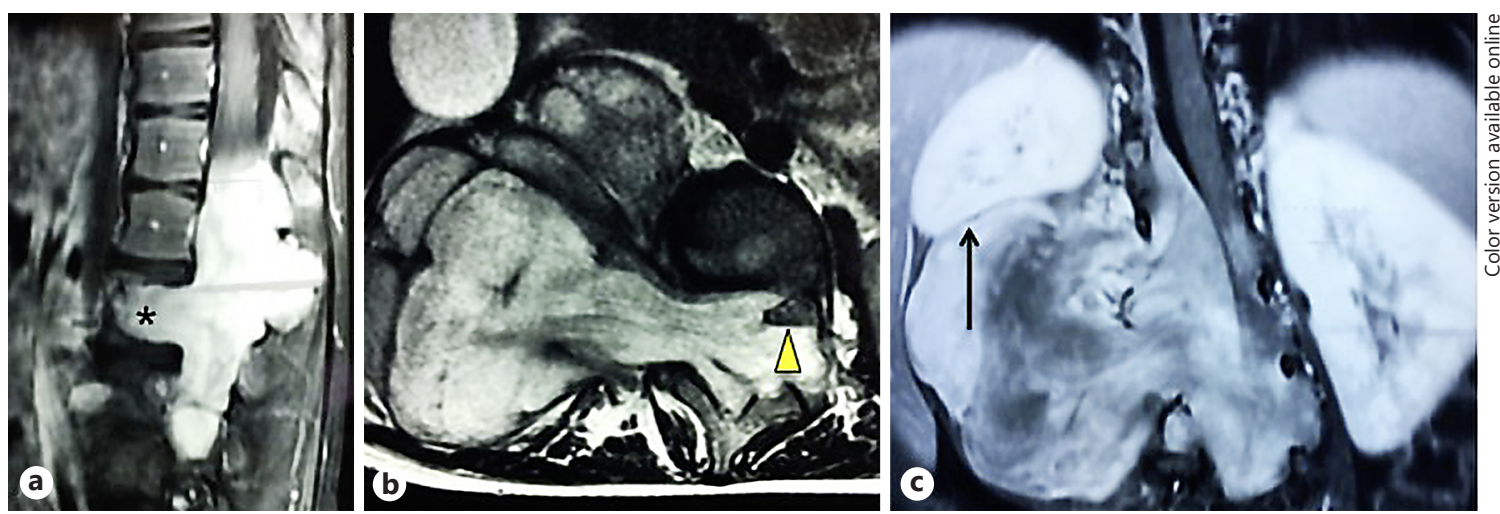

Fig. 1. MRI in sagittal (a), axial (b), and coronal (c) views. The tumor had eroded the vertebral body of L1 $\left(^{*}\right)$, had a dumbbell shape, and occupied a large portion of the spinal canal, displacing the spine to the left (arrowhead). In the retroperitoneum, the tumor displaced the right kidney upwards (arrow).

KARGER

(C) 2018 S. Karger AG, Basel

E-Mail karger@karger.com www.karger.com/pne
Pedro Tadao Hamamoto Filho, MD, MS

Departamento de Neurologia, Psicologia e Psiquiatria UNESP - Campus de Botucatu, Distrito de Rubião Jr s/n Botucatu, SP 18.618-686 (Brazil)

E-Mail phamamoto@fmb.unesp.br 


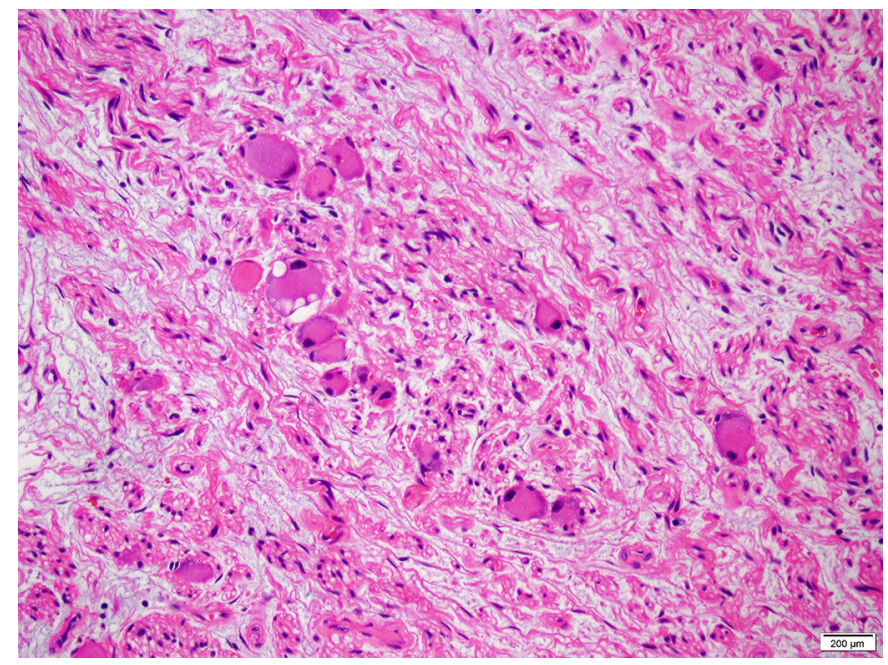

Fig. 2. Histologic analysis revealed fusiform cells with round nuclei and mature ganglion cells.

Ganglioneuromas are uncommon, benign, neoplastic tumors that originate from the primitive neural crest cells that differentiate into the sympathetic nervous system.
They belong to the group of peripheral neuroblastic tumors, and generally have a good prognosis, in contrast to neuroblastomas [1-3]. Most ganglioneuromas are located within the mediastinum and abdominal cavity. Ganglioneuromas involving the spinal canal comprise $<10 \%$ of cases [2]. The clinical presentation may vary from asymptomatic to back pain or neurological deficits [4]. On MRI, they typically exhibit hypointensity on T1 and hyperintensity on T2. As a benign tumor, complete surgical resection enables patients to be cured of this tumor, although risky adhesions to great vessels often lead to subtotal resection, which is acceptable since this tumor exhibits a very low rate of growth.

\section{Statement of Ethics}

Informed consent to publish these data was obtained from those legally responsible for the patient.

\section{Disclosure Statement}

The authors declare no conflicts of interest.

References

1 Mutluer S, Ersahin Y, Binatli O, Demirtas E: Dumbbell ganglioneuromas in childhood. Childs Nerv Syst 1993;9:182-184.

$\checkmark 2$ Pang BC, Lim T, Tan KK: Giant spinal ganglioneuroma. J Clin Neurosci 2005;12:967972.
3 Bernardi B, Gambini C, Haupt R, Granata C, Rizzo A, Conte M, et al: Retrospective study of childhood ganglioneuroma. J Clin Oncol 2008;26:1710-1716.

4 Huang Y, Liu L, Li Q, Zhang S: Giant ganglioneuroma of thoracic spine: a case report and review of literature. J Korean Neurosurg Soc 2017;60:371-374.
Santaella/Hamamoto Filho/Poliseli/ de Oliveira/Ducati/Moraes/Zanini 